\title{
Lifelong learning strategies in nursing: A systematic review
}

Mojtaba Qanbari Qalehsari ${ }^{1}$, Morteza Khaghanizadeh ${ }^{2}$, Abbas Ebadi $^{3}$

${ }^{1}$ Ph.D. Student of Nursing, School of Nursing, Baqiyatallah University of Medical Sciences, Tehran, Iran

${ }^{2}$ Ph.D. of Curriculum Studies, Associate Professor of Behavioral Sciences Research Center, Nursing Faculty, Baqiyatallah University of Medical Sciences, Tehran, Iran

${ }^{3}$ Ph.D. in Nursing Education, Associate Professor of Behavioral Sciences Research Center, Nursing Faculty, Baqiyatallah University of Medical Sciences, Tehran, Iran

Type of article: Systematic review

\begin{abstract}
Background: Lifelong learning is an expectation in the professional performance of nurses, which is directly related to the success of students in nursing schools. In spite of the considerable attention paid to this issue, lifelong learning strategies are not fully understood.

Objective: The aim of this study was to clarify lifelong learning strategies of nursing students with respect to international experience.

Methods: In this systematic review, an extensive investigation was carried out using Persian and English studies in Pub Med, ProQuest, Cochrane, Ovid, Scopus, Web of Science, SID, and Iran Doc using the following keywords: lifelong learning, self-directed learning, lifelong learning model, continuing education, nursing education, and lifelong program. Finally, 22 articles published from 1994 to 2016 were selected for the final analysis. Data extracted from the selected articles was summarized and classified based on the research questions.

Results: In this study, 8 main themes, namely intellectual and practical independence, collaborative (cooperative) learning, researcher thinking, persistence in learning, need-based learning, learning management, suitable learning environment, and inclusive growth, were extracted from the article data.

Conclusion: Having identified and clarified lifelong learning strategies in nursing, it is recommended to use the research findings in the programs and teaching systems of nursing schools. Use of strategies of lifelong learning will led to increased quality of education, development of nursing competency and finally, increased quality of patient care.
\end{abstract}

Keywords: Lifelong learning, Nursing education, Systematic review

\section{Introduction}

\subsection{Background}

Lifelong learning has been recognized as a necessity for the nursing profession (1). According to the recommendation by the I.O.M (Institute of Medicine), nurses should be involved with lifelong learning. To this end, the Accreditation Board, nursing schools, health-related organizations, and instructors should collaborate to enable nurses, nursing students, and faculty members to continue teaching and become involved with lifelong learning to acquire the qualifications required for provision of care to different societies. It is even necessary to update curricula (2). Creation of capacity for and commitment to lifelong learning is a new approach that has attracted higher education institutes, industries, and institutes that have felt this need $(3,4)$. One of the points stressed by UNESCO on the verge of the 21 st century was in regard to continuous learning in the field of health. According to the 2013 UNESCO report, one of the goals and policies of UNESCO is to reinforce policies and articles to create a lifelong learning system (5). Lifelong learning is an active process in which the student searches for knowledge and understanding and uses it to meet his/her professional lifetime needs (6). Lifelong learning includes official and non-

\section{Corresponding author:}

Associate Professor Dr. Morteza Khaghanizadeh, School of Nursing, Baqiyatallah University of Medical Sciences, Tehran, Iran. Tel: +98.2188600047, Fax: +98.2188600047, Email: khaghanizade@bmsu.ac.ir

Received: December 12, 2016, Accepted: February 07, 2017, Published: October 2017

iThenticate screening: February 04, 2017, English editing: March 04, 2017, Quality control: September 12, 2017

(C) 2017 The Authors. This is an open access article under the terms of the Creative Commons Attribution-NonCommercialNoDerivs License, which permits use and distribution in any medium, provided the original work is properly cited, the use is non-commercial and no modifications or adaptations are made. 
official learning (7), and the learner's independence (self-direction) is one of the major characteristics of lifelong learning (8-10). Studies indicated that lifelong learning has escalated and has demonstrated a developing trend (11).

\subsection{Statement of the problem and research question}

A review of studies in articles from 2000 to 2012 revealed a lack of a clear definition of lifelong learning (12). However, it is claimed that lifelong learning, positively affects growth of employees (13) as well as professional, personal, and social development in individuals (14), and it is directly related to the success of students in nursing schools (15). Related organizations are recommended to change the context for development of lifelong learning (16). However, the elements and strategies of lifelong learning are not clearly known. In spite of the strong emphasis on lifelong learning, even its prevalence is not known and people only talk about it being an essential component of professionalism (17). Identifying lifelong strategies could improve the quality of nursing education. Unfortunately, few teachers are aware of lifelong learning skills (18). To train lifelong learners, it is necessary to change nursing management and education, and if lifelong learning is fostered properly, there will be no need for continued education (17). Although numerous studies have been conducted on the notions and meanings of lifelong learning and its advantages in nursing (19-21), lifelong learning strategies in nursing have not been clearly stated and, no study has systematically clarified the elements and strategies of lifelong learning in nursing. The present research aimed at answering the following question: "What are the elements and strategies of lifelong learning for nursing students?"

\section{Material and Methods}

\subsection{Research design and search strategy}

The present systematic review study was conducted to answer the question; "What are the elements and strategies of lifelong learning for nursing students?" In this review research, an extensive search was carried out systematically using Cochran's model to find articles in Persian and English databases namely Pub Med, ProQuest, Cochrane, Ovid, Scopus, Web of Science, SID, and Iran Doc. In the preliminary search, separate and combined keywords with suitable OR/AND operators were used to combine words and keywords such as lifelong learning, self-directed learning, lifelong program, lifelong learning model, continuing education, and nursing education.

\subsection{Inclusion and Exclusion criteria}

The inclusion criteria included all the published articles about lifelong learning in health sciences in English and Persian languages in the period from 1994-2016, and the original article with qualitative and quantitative approaches and review literature and mixed-method study. The exclusion criteria included articles by unknown authors, review sections of books, recommendations, letters to chief editors, historical articles, and articles written in a language other than Persian or English. After reviewing the title and abstract of articles, 110 articles were selected for quality assessment. Articles were assessed through several steps, and finally, 22 articles were retrieved and included in the research (Figure 1).

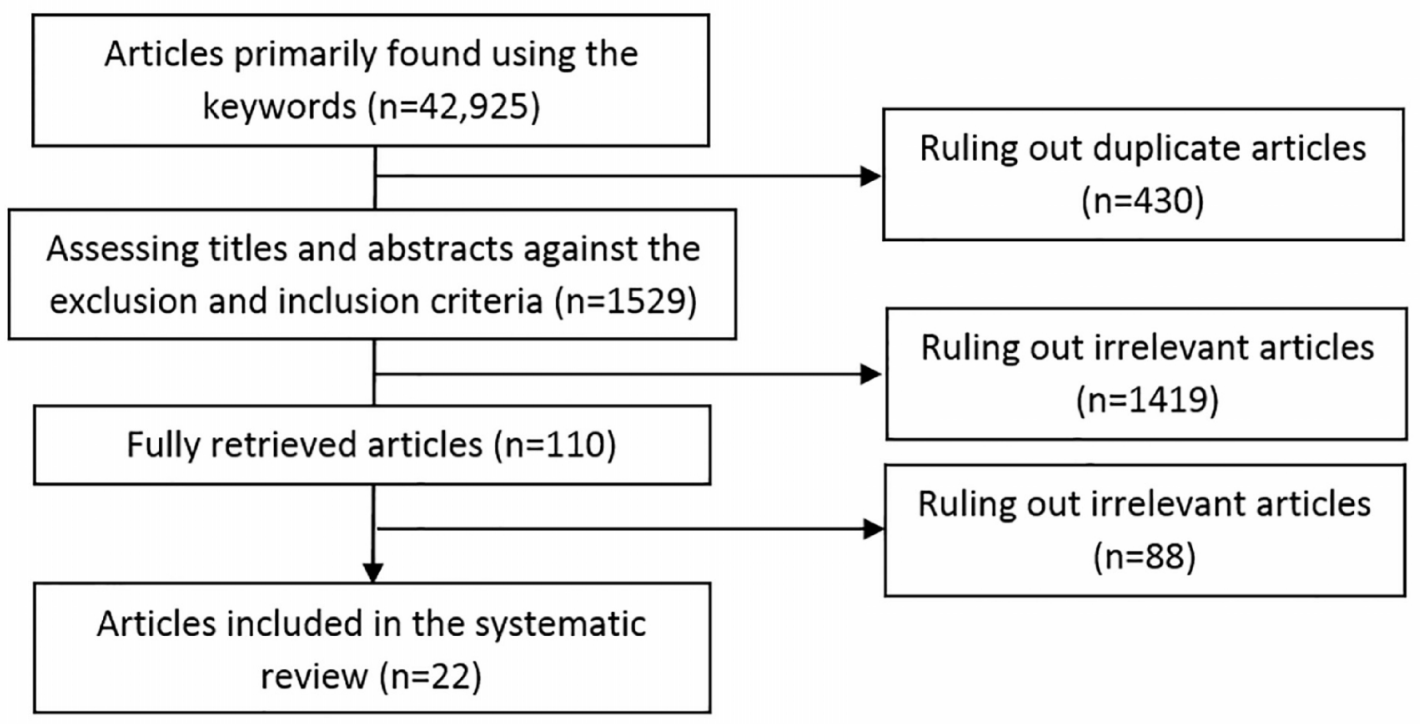

Figure 1. Article selection diagram 


\subsection{Quality assessment}

Full text of articles imported for quality assessment were carefully studied by two reviewers and reasons for rejection were listed. Evaluation criteria was mainly based on relevancy and validity of studies. In cases of dispute between the two reviewers, the third reviewer has judged. Finally, 22 articles were retrieved and included in the research (Figure 1). To extract and synthesize the data, articles were carefully studied by one of the authors, and the most important points were extracted and summarized in a narrative form in line with the research goal. Finally, findings were reported based on thematic content analysis in the form of related themes. To increase the research precision, data was controlled and revised by having the process re-examined by three other researchers in the research team.

\section{Results}

A total of 22 articles were selected for analysis in this study. The general characteristics of the studied articles are presented in Table 1. After analyzing the selected article data, 8 themes were extracted as follows, based on the research question:

Table 1. Information on articles included in the systematic review

\begin{tabular}{|c|c|c|}
\hline $\begin{array}{l}\text { Ref. } \\
\text { no. }\end{array}$ & Summary of major findings & $\begin{array}{l}\text { Research type/ Data } \\
\text { collection scale }\end{array}$ \\
\hline 22 & $\begin{array}{l}\text { Different viewpoints on critical thinking, self-directed learning through } \\
\text { problem solving, expansion of group work, persistence in work }\end{array}$ & $\begin{array}{l}\text { Mixed method / questionnaire } \\
\text { and interview }\end{array}$ \\
\hline 27 & $\begin{array}{l}\text { Five skills related to exploration creativity are: Sharing, Questioning, } \\
\text { Observing, Network, Empiricism }\end{array}$ & Functional \\
\hline 32 & $\begin{array}{l}\text { To achieve lifelong learning, continuing education should be flexible and } \\
\text { multidimensional/ requirements for continuing education to facilitate lifelong } \\
\text { learning }\end{array}$ & Systematic review \\
\hline 39 & A curriculum does not influence self-directed learning on its own. & $\begin{array}{l}\text { Quasi-experimental / } \\
\text { questionnaire }\end{array}$ \\
\hline 35 & $\begin{array}{l}\text { Interaction with system (learner, instructor, and electronic system) is a factor of } \\
\text { persistence and interest in learning. }\end{array}$ & $\begin{array}{l}\text { Quasi-experimental/ } \\
\text { questionnaire }\end{array}$ \\
\hline 36 & $\begin{array}{l}\text { Attachment to a group increases self-confidence, self-direction, and interest in } \\
\text { continued learning. }\end{array}$ & $\begin{array}{l}\text { Quasi-experimental/ } \\
\text { questionnaire }\end{array}$ \\
\hline 23 & Role of person-specific programs in people's interest in lifelong learning & $\begin{array}{l}\text { Cross-sectional/ } \\
\text { Questionnaire }\end{array}$ \\
\hline 26 & Role of internal and environmental factors and patients in lifelong learning & $\begin{array}{l}\text { Qualitative research/ semi- } \\
\text { structured questionnaire }\end{array}$ \\
\hline 25 & Raising questions about self-direction / skills fade away over time. & $\begin{array}{l}\text { Systematic review/ theme } \\
\text { analysis }\end{array}$ \\
\hline 19 & Notion of lifelong learning - behavi & Delphi \\
\hline 20 & Metaphors about lifelong learning & Qualitative and quantitative \\
\hline 24 & Role and barriers of continuing education in lifelong learning & $\begin{array}{l}\text { Descriptive - analytical / } \\
\text { questionnaire }\end{array}$ \\
\hline 27 & 6 competencies for self-directed learning & Discussion \\
\hline 29 & Basic principles of self-directed learning & Systematic review \\
\hline 31 & Viewpoints of teachers and students on self-directed learning notions & $\begin{array}{l}\text { Qualitative research/ } \\
\text { interview }\end{array}$ \\
\hline 28 & Facilitators and barriers of self-directed learning & Qualitative - focus group \\
\hline 34 & Barriers and strategies of self-directed learning & $\begin{array}{l}\text { Qualitative study - interview } \\
\text { - self-report }\end{array}$ \\
\hline 38 & $\begin{array}{l}\text { Lecturing environment along with learning are more effective than learning, } \\
\text { depending on the case. }\end{array}$ & $\begin{array}{l}\text { Quasi-experimental/ } \\
\text { questionnaire }\end{array}$ \\
\hline 41 & Action organizations are strong stimuli for involvement in lifelong learning & discussion \\
\hline 33 & $\begin{array}{l}\text { Motivation factors, education priorities, and need assessment in continuing } \\
\text { education }\end{array}$ & Systematic review \\
\hline 30 & $\begin{array}{l}\text { Teaching critical thinking, problem solving, and metacognition positively affect } \\
\text { self-directed learning }\end{array}$ & RCT questionnaire \\
\hline 40 & Thinking style is related to self-directed learning. & $\begin{array}{l}\text { Descriptive- correlational / } \\
\text { questionnaire }\end{array}$ \\
\hline
\end{tabular}




\subsection{Intellectual and Practical Independence}

Research results revealed that development of learning skills can contribute to intellectual and practical independence (22-28). Students prefer practical and actual environments for development of their skills, which does not occur in only one course (22). Skills such as communication and technical skills are gained through interaction with patients (26). Learning problem solving skills can contribute to intellectual and practical independence (22, 29, $30)$. Critical thinking in learning grows with the problem-solving approach $(22,30)$ and helps individuals think, function, and search for information independently (22). Flexible and critical thinking contributes to people's intellectual and practical independence in attaining lifelong learning goals $(19,22,26,27,30,31)$. Research results suggest that lifelong learners have a critical thinking style and select different ways of searching (22). Teaching with an invariant approach inhibits critical thinking, and people prefer a combination of different teaching methods (22). Another approach for attainment of intellectual and practical independence is emphasizing diverse skills. In this regard, particular attention is paid to the role of continuing education, which should be focused on diverse skills (24, 32,33 ). Continuing education should include all of the self-directed learning activities (32) rather than solely focusing on cognitive dimensions of nursing $(32,33)$. Continuing education programs should be flexible, and structured continuing education may inhibit self-directed learning (24). Reflective skills, creativity, and critical thinking, which are required to transform knowledge into practice, are requirements that need to be stressed in teaching (32). Interpersonal skills are among the skills that are gained through collaborative training and interactive workshops (32). Teaching by different methods leads to improvement of different skills, and students and employees prefer to receive training with a combination of different methods (34). Intellectual and practical independence is facilitated with independence in learning. A learning portfolio gives independent learners reflective thoughts (29).

\subsection{Collaborative Learning}

Collaborative learning results from group learning $(22,26,32)$, learning from others $(19,26,32)$, interacting with learning agents $(19,35)$, empathy (26), and belongingness (36) within a suitable group processes context (22). Group work is useful for opening the minds of students, because opinions of other group members foster thinking. By sharing one's production with others it is possible to inform them of their operational flaws (22). Learning is even obtained by observing colleagues (26). The person should be aware of his/her role in the team, and colleagues and care providers' teams can be other sources of learning (26). Taking care of patients can be considered part of collaborative learning (19). Development of new connections is known as part of collaborative learning and one of the notions of lifelong learning (19). This interaction and relationship may be between the education system, learner, and instructor (35). In electronic learning, the person's interaction with the electronic system is considered the environment component of collaborative learning (35). Interaction context should also be available for collaborative learning. Hence, students, professors, and curricula should be in harmony for the purpose of self-directed lifelong learning (35). Proportions between professors, students, classes, and desirable physical environments can affect quality of group work and interaction (35). Belongingness and empathy are the requisites for group learning. Belongingness is positively related to self-directed learning and invokes satisfaction in the learner (36).

\subsection{Researcher Thinking}

According to the research review, researcher thinking includes exploration skills $(23,37)$, continued brain activity, involvement in research-based learning, questioning, reinforcement of curiosity (19), reflection $(19,26,27,34)$, searching for knowledge and skills, and observational learning (19). Lifelong learners are curious explorers (19), who question the environment $(19,26)$. They appreciate new ideas and are interested in learning new skills $(19,23)$. They actively become involved in learning like researchers (19), and reflect the points due to the significance of learning $(19,26,27,34)$. Exploration skills are gained through interaction with the realm of knowledge (37). Although creative people always expect new possibilities (28), to raise creative humans, their power of observation also needs to be improved in addition to their communicative skills (37). In addition to observation, experiencing and using a learning network also contribute to reinforcement of exploration skills (37).

\subsection{Persistence in Learning}

Persistence in learning is achieved through development of skills and acquisition of new skills. These skills are gained by a method of teaching aimed at increasing learning skills and attaining new methods of learning rather than scoring. Teaching skills especially communicative, technical, and clinical skills $(23,26)$ in an actual environment (22) with emphasis on learning methods $(19,20)$, improves self-confidence of people in learning and encourages them to learn $(19,26)$. In this path, it is possible to use compulsion in cases of individuals not interested in learning (32). Since after ruling out the re-learning score some people may refuse to take part in learning, first it is necessary 
to support them in learning (38), and then force them to learn and become familiar with others' experience. Evidently, various skills should be employed in teaching, to facilitate and encourage people in learning $(24,38)$.

\subsection{Need-Based Learning}

Teaching and learning should be based on the needs of stakeholders involved in education $(25,32)$. Students and patients are the most important stakeholders of education (32). Continuing education should be particularly aimed at improvement rather than elimination of standards. Continuing education should improve patient output and should meet the needs of students and patients. However, assessment of continuing education does not assess the technical dimension of care provision (32). Ease of education is another requirement (35). The easier a system is to use, the higher the interest is in it. As a result, performance improves and learning becomes enjoyable (35). Enjoying learning is one of the concepts of lifelong learning $(32,35)$. It is a passive mechanism which brings such an assignment to the individual that detaches them from the environment and consumes them. The result of this process is improvement of determination. Hence, need-based teaching, ease and joy of learning lead to continuous job satisfaction $(19,36)$, and thus students need to know what they should learn $(23,28,29,31,34)$. Identification of students' needs brings about commitment to learning, which is a principal component of self-directed learning (19, $20,29)$. Need for learning sometimes leads to self-improvement $(19,26,28)$, and nurses particularly, need to sometimes learn due to personal challenges and professional qualification (26). Attainment of goal is another factor involved in inclination toward learning. Attainment of learning goals increases interest in lifelong learning $(23,25$, $29,34)$. Need for learning can also allow for earning society's trust $(19,26)$ or using learning in practice (19). A student's needs can be revealed by the student himself/herself or a teacher. The teacher facilitates satisfaction of student's needs for self-directed learning, especially on the professional and clinical levels $(28,29,31)$. However, professors and students may have different viewpoints in this regard. According to some teachers, self-directed learning may limit students (31), whereas students believe self-directed learning is completely need-dependent (23, $28,31)$. In spite of the viewpoint differences, professors' control over students along with assignment of tasks, helps self-directed learning (31). A student's emphasis on a need enables them to design a unique learning program, which improves lifelong learning (23). Identification of person-specific strategies in learning, influence lifelong learning $(23,34)$. In this regard, development of a personal program also contributes to emergence of interest in lifelong learning $(23,34)$. Any problem in development and implementation of the program whether it is a curriculum or a personal program, is a barrier to lifelong learning $(23,34)$. It should be noted that a curriculum does not influence self-directed learning on its own (39), and lack of an alternative program when the primary program cannot be implemented, inhibits lifelong learning (34). As a result of identification of needs, people become interested in more subjects and learning (40).

\subsection{Learning Management}

Learning management includes self-assessment $(22,34,39,40)$, goal setting $(23,25,28,29,34)$, goal and strategy selection $(23,34,38)$, knowledge translation (19), time management $(26,34)$, knowledge management $(26,34)$, and internal and external responsiveness (34). Self-assessment of lessons to be learned as well as one's self and others' is one of the competencies required for self-directed learning $(22,27,40)$. Internal responsiveness results from selfreflection and self-assessment $(27,34)$. In learning management, after conducting a self-assessment and understanding one's own learning deficits, the learner needs to set goals. In setting goals, identification of support sources is necessary, and the most important source of support is clear educational goals $(28,29)$. Any problem in setting goals, undoubtedly prevents attainment of self-directed learning $(23,28,34)$. Moreover, development of learning goals, which is a component of self-directed learning $(23,29,34)$, influences the search for knowledge and observation-based actions (25). Learning strategies should be measureable, realistic, timed, and actual (34). Selection of more important goals is the first priority, and proper actualization of these goals is an important strategy in successful learning $(28,38)$. In learning management, the person should possess knowledge translation (19), time management, and knowledge management $(26,27)$ skills in the program implementation phase. The learner should act such that they can respond to themselves, the faculty, and their colleagues (34).

\subsection{Suitable Learning Environment}

A learning environment is a setting in which the learning environment stresses are minimized $(26,34)$, professors are fully aware of lifelong and self-directed learning $(29,31)$, the educational structure suits learning $(23,32)$, relevant organizations participate in education (41), and education is carried out using quality methods (24) and continued education methods $(24,32,33)$. Personality, destructive relationships, and contradictions in the learning environment prevent learning (Huggins, 2004). Time shortage and work pressure negatively affect learning opportunities $(26,34)$. Lack of adequate time for procedures $(34)$, fatigue, time pressure, and a regular program are 
known as environmental stress factors inhibiting lifelong learning $(26,34)$. Professors and teachers facilitate lifelong learning $(29,31)$. Hence, professors substantially need development $(28)$, because some professors lack adequate information on actualization of self-directed learning $(28,31)$, and there are differences among teachers in implementation of self-directed learning (28). Lifelong learning calls for support sources. Lifelong learning sources include structured yet flexible education $(28,32)$. In addition, establishment of an action organization can stimulate lifelong learning (41). These organizations regulate the need for self-directed learning and structure and provide feedback on reflective, experimental, and academic lifelong learning. Continuing education along with action, organizations play an important role in the continuation of learning. Content and method of implementation of a continuing education program can create a desirable learning environment and stimulate learning provided that it is satisfactory $(24,32,33)$.

\subsection{Inclusive Growth}

Inclusive growth requires intelligence, spirituality, physical and mental dimensions (19), sustainable development $(19,20)$, improvement of personality $(19,26)$, and improvement of capacity $(19,32)$. It results in improvement of self-confidence $(26,34,36)$, acquisition of society's trust and partial human development (19). Some of the notions associated with lifelong learning include intelligence, spirituality, physical and mental dimensions (19), and sustainable development and change (19). Nurses need to learn to achieve self-development. Personal challenges, progression, and qualification for the job are other reasons for learning (26). On the other hand, fear of failure prevents reflection of problems and self-directed learning (19). In addition to personal improvement, it is useful to society when a person wins the society's trust (19).

\section{Discussion}

This systematic review resulted in discovery of 9 themes regarding elements and strategies of lifelong learning in nursing students. Most students emphasized employees' development rather than students' development. Therefore, very few studies have been solely dedicated to lifelong learning in nursing students. In spite of the emphasis on lifelong learning, reviews of studies published from 2000 to 2014 did not lead to a clear definition of lifelong learning (12). However, if lifelong learning is truly fostered in nurses, there will be no need for continuing education (42). In this research, data bases were systematically reviewed and 8 themes associated with lifelong learning elements, and strategies were extracted. Intellectual and practical independence was one of the themes, and results from development of skills, learning to solve problems, flexible thinking, focusing on diverse skills in continuing education, openness, and independence in learning. Numerous studies have stressed development of problem solving skills and its effect on lifelong learning (30,43-45). Embo et al. introduced 'concentration on development of competencies' as a tool for developing self-directed learning (46). Although various studies have introduced independence and self-direction as elements of learning, in a study conducted to compare satisfaction of students in two student groups (a group worked under supervision of a preceptor and another group worked independently), satisfaction of students in the group working under the supervision of the preceptor was higher than the self-directed group that worked independently (47). Intellectual and practical independence is only one of the elements of lifelong learning as it completes a whole along with other elements. This is because intellectual and practical independence cannot affect practical activities and courses alone. Independent learning was not effective in activities such as electrocardiogram teachings as compared to workshops and lectures (48). Collaborative learning was another theme extracted from this research. Collaborative learning refers to group learning, interaction with learning agents, satisfactory communication, learning from others, belongingness, and empathy. Since nursing is a group activity in a hospital, a suitable platform for group activities can be created in society or university. In a study, self-confidence and belongingness explained $37 \%$ of self-directed learning (36). Studies also suggest that working in small groups positively influences motivation and self-directed learning (22). The suitable platform for group activities is created by regulating the professor-student proportions and providing basic facilities such as suitable classrooms and satisfactory physical environments (19). Researcher thinking was another theme extracted from this study as a lifelong learning strategy. The researcher thinking style invokes curiosity in individuals and enables them to eagerly search for new solutions and skills $(19,23)$. Acquisition of exploration skills stimulates creativity and transference of knowledge (37). Establishment of proper relationships plays a key role in collaborative learning and the art of effective communication is a requisite for lifelong learning (49). Another theme that is necessary for lifelong learning is persistence in learning, which is achieved through continuing education in today's nursing education systems. Continuing professional education, positively affects persistence in learning medical sciences (50). However, participation in continuing education may be for the purpose of scoring, and a group of researchers believe that the number of participants drops after omitting re-learning scores $(32,33)$. On the other hand, financial problems, time shortage, and family problems may be barriers to continued learning (24). For continued learning, 
new skills and learning skills should be taught, because nurses believe that acquisition of knowledge increases their self-confidence by supporting skills and abilities $(19,26)$. Problem solving exercises improve learning skills (51). Continuing education is utilized as a means of continued learning with the aid of compulsion. Although some researchers disagree with forced learning, studies have revealed that by forcing uninterested people into learning they are driven toward lifelong learning (32). In another study, nurses expressed their experience with education, and three themes, namely inadequate tendency for forced education, inadequate support, and passive educational supervision, were obtained (52). In addition to lack of tendency for education, supervision is a serious issue in this regard. If learning is based on needs (one of the themes extracted from this research), interest in learning grows, and forced education loses significance. In need-based learning, attention should be paid to education stakeholders (32). The most important challenge in need-based learning is identification of learning needs $(28,29,31,34)$. Many factors such as program, professor-student mutual understanding, ease and joy of learning, and attainment of goals are involved in need-based learning. Personal commitment $(19,20,29)$ and social commitment (49) to conservation of competency can be another learning requirement. Conservation and improvement of competency is necessary for self-improvement or for earning society's trust $(19,26,28)$. Miller et al. (1998) introduced motivation at time of employment, and values as the motivation factors in learning. They recommended auditing motivations of clinical employees (53).

Learning management is another lifelong learning strategy. In this study, learning management refers to selfassessment, goal setting, knowledge management, time management, goal selection, strategy, and internal and external responsiveness. In a 2002 study by Patterson et al., they referred to self-assessment, assessment of others, reflection, and information management as self-directed learning skills (27). In a 2009 study by Collins, selfassessment was introduced as a lifelong learning activity (49). In a 2010 study by $\mathrm{Li}$ et al., they introduced goal setting and persistence in program implementation as a means of lifelong learning (34). Learning management is a strategy required for principled lifelong learning. The learning environment is another underlying requirement for achievement of lifelong learning. In addition to environmental stresses and participation of action organizations, the highest level of emphasis is put on the environment of the teachers and professors. In a 2007 study by Alavi and Abedi, they introduced the presence of an effective tutor as a factor involved in the creation of a suitable working environment for professional growth (54). Teachers play a substantial role in motivating students, and thus teachers need to support students' learning programs $(54,55)$. Many studies have referred to mentoring as an environmental component of education and have described characteristics of a mentor (56) as well as the effect of mentoring on clinical performance and satisfaction of students and employees $(45,47,54,57,58)$. Students also tend to work under the supervision of a professor and faculty rather than on their own (59). However, a 2014 study by Çelebi et al. showed that professors are slightly aware of lifelong learning skills (18). This finding reflects the necessity of professors' concerns for reinforcement of lifelong learning skills. Universities also play a determining role in supporting lifelong learning as regards to learning, learning needs, and professional development (60). There are different views on the effect of programs on lifelong learning. For instance, Andersen showed that an official training program that lasts for one or several days, more effectively influences continuity of competence than nonofficial programs (61). However, a 2003 study by Harvey et al. showed that students' self-directed learning is not influenced by programs (39). According to this research, one factor cannot lead to lifelong learning alone as a collection of conditions and skills results in lifelong learning. The last theme resulted from the review was inclusive growth, which refers to a form of growth in different human dimensions such as intellectual, spiritual, physical, mental, personality, and social dimensions. Different studies have revealed that lifelong learning positively influences growth of employees (13). Professional and personal development and social development were the strongest motivations for continuing education (14). Notions of mentoring and role modeling are raised in discussion of inclusive growth, because role modeling positively affects professional satisfaction and personality $(57,58)$ and it is strongly related to nurses' personal growth (62). Studies also introduced sustainable development and change as part of inclusive growth, which is a component of lifelong learning $(19,20)$. Self-construction is another meaning of lifelong learning, which is part of a person's inclusive growth (42). Results of this study showed that lifelong learning strategies in nursing include students, teachers and organizational activity, and coordination of these factors are required to achieve lifelong learning. This study has some limitation such as shortage of research studies with different approaches in the area of lifelong learning in nursing. Limited qualitative and quantitative studies indicate the necessity of more attention and research regarding lifelong strategies in nursing.

\section{Conclusions}

In this research, over 42,000 studies with a broad geographical distribution were reviewed using keywords related to lifelong learning. It is recommended to use results of this research in education and programs of nursing and other 
medical sciences fields, because if lifelong learners are raised there will be no need for continuing education, and use of lifelong strategies in nursing students will lead to improved quality of education, professional competency of nurses and nursing care outcomes. A study to use elements and strategies of lifelong learning in nursing programs is also recommended.

\section{Acknowledgments:}

The preset study is a part of a large study and it is extracted from a Ph.D. thesis in nursing. In this regard, we thank and appreciate the cooperation of the nursing college and the Behavioral Sciences Research Center of Baqiyatallah Medical Sciences University.

\section{Conflict of Interest:}

There is no conflict of interest to be declared.

\section{Authors' contributions:}

All authors contributed to this project and article equally. All authors read and approved the final manuscript.

\section{References:}

1) NLN. Academic progression in nursing education: a living document from the National League for Nursing. 2011.

2) Institute of Medicine. Committee on Planning a Continuing Health Care Professional Education Institute. Redesigning continuing education in the health professions. Washington (DC): The National Academies Press; 2010.

3) Kember D, Leung D, Ma R. Characterising learning environment capable of nurturing generic capabilities in higher education. Research in Higher Education. 2007; 48: 609-31. doi: 10.1007/s11162-006-9037-0.

4) Ambrósio S, Araújo e Sá MH, Simões AR. Lifelong Learning in Higher Education: The Development of Non-traditional Adult Students' Plurilingual Repertoires. Procedia - Social and Behavioral Sciences. 2014; 116: 3798-804. doi: 10.1016/j.sbspro.2014.01.844.

5) UNESCO Institute for Lifelong Learning. Annual Report 2013. 2014.

6) Nayda N, Rankin E. Information literacy skill development and life long learning: exploring nursing students' and academics' understandings. Australian Journal of Advanced Nursing. 2008; 26(2): 27-33.

7) Tan C, Morris J. Undergraduate college students, laptop computers, and lifelong learning. The Journal of General Education. 2005; 54(4): 316-38. doi: 10.1353/jge.2006.0013.

8) O'Shea E. Self-directed learning in nurse education: a review of the literature. J Adv Nurs. 2003; 43(1): 6270. doi: 10.1046/j.1365-2648.2003.02673.x. PMID: 12801397.

9) Winch C. Learning how to learn: a critique. Journal of Philosophy of Education. 2008; 42(3-4): 649-65. doi: 10.1111/j.1467-9752.2008.00644.x.

10) Ponton M, Cerrick M, Carr P. The relationship between resourcefulness and persistence in adult autonomous learning. Adult Education Quarterly. 2005; 55(2): 116-28. doi: 10.1177/0741713604271848.

11) Yousefi A, Gordanshekan M. A review of self-directed learning development. Iranian Journal of Education in Medical Sciences. 2010; 10(5): 776-83.

12) Dehnad A, Afsharian F, Hosseini F, Arabshahi SKS, Bigdeli S. Pursuing a Definition of Self-directed Learning in Literature from 2000-2012. Procedia - Social and Behavioral Sciences. 2014; 116(0): 5184-7. doi: 10.1016/j.sbspro.2014.01.1097

13) Ionela AM. The Role of Lifelong Learning in the Growth of Employment and Labour Efficiency. The Case of Romania. Procedia - Social and Behavioral Sciences. 2012; 46(0): 4399-403. doi: 10.1016/j.sbspro.2012.06.262.

14) Laszlo H, Strettle RJ. Midwives' motivation for continuing education. Nurse education today. 1996; 16(5): 363-7. doi: 10.1016/S0260-6917(96)80010-4.

15) Avdal EU. The effect of self-directed learning abilities of student nurses on success in Turkey. Nurse education today. 2013; 33(8): 838-41. doi: 10.1016/j.nedt.2012.02.006.

16) Ryan D, Waterston R. Transforming continuing education materials for on-line learning. J Telemed Telecare. 2000; 6 Suppl 2: S64-6. doi: 10.1258/1357633001935626. PMID: 10975107.

17) Jarvis P. Lifelong education and its relevance to nursing. Nurse education today. 2005; 25(8): 655-60. doi: 10.1016/j.nedt.2005.09.005. 
18) Çelebi N, Özdemir H, Eliçin Ö. Studying Level of Awareness of Teachers in Terms of their Lifelong Learning Skills. Procedia - Social and Behavioral Sciences. 2014; 116(0): 2030-8. doi: 10.1016/j.sbspro.2014.01.515.

19) Davis L, Taylor H, Reyes H. Lifelong learning in nursing: a Delphi study. Nurse Educ Today. 2014; 34(3): 441-5. doi: 10.1016/j.nedt.2013.04.014. PMID: 23664106.

20) Şenyuva E, Çalı̧̧kan F. Lifelong Learning Perception Metaphoric of Nurses. Procedia - Social and Behavioral Sciences. 2014; 152(0): 372-8. doi: 10.1016/j.sbspro.2014.09.214.

21) Ainoda N, Onishi H, Yasuda Y. Definitions and goals of "self-directed learning" in contemporary medical education literature. Ann Acad Med Singapore. 2005; 34(8): 515-9. PMID: 16205831.

22) Chiang VCL, Leung SSK, Chui CYY, Leung AYM, Mak YW. Building life-long learning capacity in undergraduate nursing freshmen within an integrative and small group learning context. Nurse education today. 2013 ; 33(10): 1184-91. doi: 10.1016/j.nedt.2012.05.009.

23) Li ST, Tancredi DJ, Co JP, West DC. Factors associated with successful self-directed learning using individualized learning plans during pediatric residency. Acad Pediatr. 2010; 10(2): 124-30. doi: 10.1016/j.acap.2009.12.007. PMID: 20206911.

24) Lee AC, Tiwari AF, Hui Choi EW, Yuen KH, Wong A. Hong Kong nurses' perceptions of and participation in continuing nursing education. J Contin Educ Nurs. 2005; 36(5): 205-12. PMID: 16218008.

25) Horsley T, O'Neill J, McGowan J, Perrier L, Kane G, Campbell C. Interventions to improve question formulation in professional practice and self-directed learning. Cochrane Database Syst Rev. 2010; (5): Cd007335. doi: 10.1002/14651858.CD007335.pub2. PMID: 20464753.

26) Huggins K. Lifelong learning--the key to competence in the intensive care unit? Intensive Crit Care Nurs. 2004; 20(1): 38-44. doi: 10.1016/j.iccn.2003.10.001. PMID: 14726252.

27) Patterson C, Crooks D, Lunyk-Child O. A new perspective on competencies for self-directed learning. J Nurs Educ. 2002; 41(1): 25-31. PMID: 11843104.

28) Lunyk-Child OI, Crooks D, Ellis PJ, Ofosu C, O'Mara L, Rideout E. Self-directed learning: faculty and student perceptions. J Nurs Educ. 2001; 40(3): 116-23. PMID: 11302539.

29) Murad MH, Varkey P. Self-directed learning in health professions education. Ann Acad Med Singapore. 2008; 37(7): 580-90. PMID: 18695772.

30) Nadi MA, Gordanshekan M, Golparvar M. Effect of critical thinking, problem solving, and metacognition teaching on self-directed learning in students. Research in Curricula. 2011; 8(1-2): 53-61.

31) Hewitt-Taylor J. Self-directed learning: views of teachers and students. J Adv Nurs. 2001; 36(4): 496-504. doi: 10.1046/j.1365-2648.2001.02001.x. PMID: 11703543.

32) Griscti O, Jacono J. Effectiveness of continuing education programmes in nursing: literature review. J Adv Nurs. 2006; 55(4): 449-56. doi: 10.1111/j.1365-2648.2006.03940.x. PMID: 16866840.

33) Ebadi A, Vanaki Z, Nahrir B, Hekmatpour D. Pathology of Continuing Educational Programs in Iran Medical Society. Strides Dev Med Educ. 2007; 4(2): 140-5.

34) Li ST, Paterniti DA, Co JP, West DC. Successful self-directed lifelong learning in medicine: a conceptual model derived from qualitative analysis of a national survey of pediatric residents. Acad Med. 2010; 85(7): 1229-36. doi: 10.1097/ACM.0b013e3181e1931c. PMID: 20592521.

35) Cheng YM. Exploring the roles of interaction and flow in explaining nurses' e-learning acceptance. Nurse education today. 2013; 33(1): 73-80. doi: 10.1016/j.nedt.2012.02.005.

36) Kim M, Park SY. Factors Affecting the Self-directed Learning of Students at Clinical Practice Course for Advanced Practice Nurse. Asian Nurs Res (Korean Soc Nurs Sci). 2011; 5(1): 48-59. doi: 10.1016/s19761317(11)60013-3. PMID: 25029949.

37) Armstrong EG, Barsion SJ. Creating "innovator's DNA" in health care education. Acad Med. 2013; 88(3): 343-8. doi: 10.1097/ACM.0b013e318280cb7b. PMID: 23348085.

38) Baeten M, Dochy F, Struyven K. The effects of different learning environments on students' motivation for learning and their achievement. Br J Educ Psychol. 2013; 83(Pt 3): 484-501. doi: 10.1111/j.20448279.2012.02076.x. PMID: 23822533.

39) Harvey BJ, Rothman AI, Frecker RC. Effect of an undergraduate medical curriculum on students' selfdirected learning. Acad Med. 2003; 78(12): 1259-65. doi: 10.1097/00001888-200312000-00015. PMID: 14660430 .

40) Veiskarami H, Geravand H, Naserian H, Afsharizade SE, Montazeri R, Mohammadzade Qasr A. A comparative analysis of functions of thinking style with self-directed learning in nursing and midwifery students of Mashhad University of Medical Sciences. Research in Medical Sciences Education. 2012; 4(2): 53-62. 
41) Frankford DM, Patterson MA, Konrad TR. Transforming practice organizations to foster lifelong learning and commitment to medical professionalism. Acad Med. 2000; 75(7): 708-17. doi: 10.1097/00001888200007000-00012. PMID: 10926021.

42) Talati JJ. Lifelong learning: Established concepts and evolving values. Arab Journal of Urology. 2014; 12(1): 86-95. doi: 10.1016/j.aju.2013.11.001.

43) Miflin BM, Campbell CB, Price DA. A conceptual framework to guide the development of self-directed, lifelong learning in problem-based medical curricula. Med Educ. 2000; 34(4): 299-306. doi: 10.1046/j.1365-2923.2000.00564.x. PMID: 10733727.

44) Hosseini Bidokht M, Assareh A. Life-long learners through problem-based and self directed learning. Procedia Computer Science. 2011; 3: 1446-53. doi: 10.1016/j.procs.2011.01.028.

45) Harun NF, Yusof KM, Jamaludin MZ, Helmi Syed Hassan SA. Motivation in Problem-based Learning Implementation. Procedia - Social and Behavioral Sciences. 2012; 56(0): 233-42. doi: 10.1016/j.sbspro.2012.09.650.

46) Embo M, Driessen E, Valcke M, van der Vleuten CP. A framework to facilitate self-directed learning, assessment and supervision in midwifery practice: a qualitative study of supervisors' perceptions. Nurse Education in Practice. 2014; 14(4): 441-6. doi: 10.1016/j.nepr.2014.01.015.

47) Omer TY, Suliman WA, Thomas L, Joseph J. Perception of nursing students to two models of preceptorship in clinical training. Nurse Educ Pract. 2013; 13(3): 155-60. doi: 10.1016/j.nepr.2013.02.003. PMID: 23485569.

48) Mahler SA, Wolcott CJ, Swoboda TK, Wang H, Arnold TC. Techniques for teaching electrocardiogram interpretation: self-directed learning is less effective than a workshop or lecture. Med Educ. 2011; 45(4): 347-53. doi: 10.1111/j.1365-2923.2010.03891.x. PMID: 21401682.

49) Collins J. Lifelong learning in the 21st century and beyond. Radiographics. 2009; 29(2): 613-22. doi: 10.1148/rg.292085179. PMID: 19325069.

50) Trewet CB, Fjortoft N. Evaluation of the impact of a continuing professional development worksheet on sustained learning and implementing change after a continuing pharmacy education activity. Res Social Adm Pharm. 2013; 9(2): 215-21. doi: 10.1016/j.sapharm.2012.06.002. PMID: 22999803.

51) Kell C, van Deursen R. Does a Problem-solving Based Curriculum Develop Life-long Learning Skills in Undergraduate Students? Physiotherapy. 2003; 89(9): 523-30. doi: 10.1016/S0031-9406(05)60178-2.

52) Vaezi A, Vanaki Z, Ahmadi F. Clarification of nurses experience with the nursing continuing education context: a qualitative study. Yazd Medical Sciences Education Development and Studies Center. 2012; 7(3): 2-15.

53) Miller J, Bligh J, Stanley I, al Shehri A. Motivation and continuation of professional development. Br J Gen Pract. 1998; 48(432): 1429-32. PMID: 9800406, PMCID: PMC1313141.

54) Alavi M, Abedi HA. Nursing students experience and understanding of the notion of effective tutor in clinical education. Iranian Journal of Medical Sciences Education. 2007; 7(2): 325-34.

55) Klug J, Krause N, Schober B, Finsterwald M, Spiel C. How do teachers promote their students' lifelong learning in class? Development and first application of the LLL Interview. Teaching and Teacher Education. 2014; 37: 119-29. doi: 10.1016/j.tate.2013.09.004.

56) Chow FLW, Suen LKP. Clinical staff as mentors in pre-registration undergraduate nursing education: students' perceptions of the mentors' roles and responsibilities. Nurse Educ Today. 2001; 21(5): 350-8. doi: 10.1054/nedt.2001.0569. PMID: 11403581.

57) Mokhtari Nouri J, Ebadi A, Alhani F, Rejheh N. Importance of model-based teaching in educating nursing students. Education Strategies. 2010; 3(4): 149-54.

58) Karimi Movasaqi H, Yazdi Moqadam H. Role modeling and mentoring in nursing education: a review. Journal of Research in Medical Sciences Education, Gilan University of Medical Sciences. 2014; 6(1): 5870.

59) Lioyd-Jones G, Hak T. Self-directed learning and student pragmatism. Adv Health Sci Educ Theory Pract. 2004; 9(1): 61-73. doi: 10.1023/B:AHSE.0000012228.72071.1e. PMID: 14739762.

60) Duke C, Hinzen H. University Engagement and the Post-2015 Agenda. What are the Roles and Functions to Support Adult Education and Lifelong Learning? Procedia - Social and Behavioral Sciences. 2014; 142(0): 29-35. doi: 10.1016/j.sbspro.2014.07.582.

61) Andersen LT. Occupational therapy practitioners' perceptions of the impact of continuing education activities on continuing competency. Am J Occup Ther. 2001; 55(4): 449-54. PMID: 11723990.

62) Glass N, Walter R. An experience of peer mentoring with student nurses: enhancement of personal and professional growth. J Nurs Educ. 2000; 39(4): 155-60. PMID: 10782759. 